\title{
Recorded prevalence of nasal polyps increases with age
}

\author{
Filip Raciborski ${ }^{1}$, Magdalena Arcimowicz ${ }^{2}$, Bolesław Samoliński ${ }^{1}$, Wojciech Pinkas ${ }^{3}$, Piotr Samel-Kowalik ${ }^{1}$, \\ Andrzej Śliwczyński ${ }^{4,5}$
}

\begin{abstract}
${ }^{1}$ Department of Prevention of Environmental Hazards and Allergology, Medical University of Warsaw, Warsaw, Poland ${ }^{2}$ Department of Otorhinolaryngology, Head and Neck Surgery, Medical University of Warsaw, Warsaw, Poland ${ }^{3}$ Department of Otolaryngology, Central Clinical Hospital of the Ministry of the Interior and Administration, Warsaw, Poland ${ }^{4}$ National Health Fund, Warsaw, Poland

${ }^{5}$ Satellite Campus in Warsaw, University of Humanities and Economics in Lodz, Poland
\end{abstract}

Adv Dermatol Allergol 2021; XXXVIII (4): 682-688

DOI: https://doi.org/10.5114/ada.2020.99365

\begin{abstract}
Introduction: Nasal polyps are a multifactorial inflammatory condition of the upper airways. Nasal polyps typically affect middle-aged and elderly patients, average age at diagnosis is 40 to 60 , and men are affected more commonly than women.

Aim: To analyse the reported prevalence of nasal polyps in the Polish population, including demographics and co-morbidities, and to estimate the costs of outpatient and hospital (inpatient) services financed by the National Health Fund. Material and methods: Statistical analysis of data extracted from the National Health Fund (NHF) registers for 20082018.

Results: In 2018, the recorded prevalence of nasal polyps in Poland was 52.0/10,000 population (0.52\%), amounting to $64.6 / 10,000(0.65 \%)$ in men and $40.2 / 10,000(0.40)$ in women. Nasal polyps were much more frequent in patients aged 55-59 (98.1/10000) and 75-79 years $(98.7 / 10,000)$. Among men, the highest prevalence was found in the 75-79 age group (164.3/10,000 population), and among women in the 55-59 age group (75.1/10,000). In 2018, the Polish NHF spent PLN 17.2 million (equivalent to EUR 4.0 million/USD 4.7 million) on health services related to the diagnosis of nasal polyps. Hospital services accounted for $77.4 \%$ of the total cost.

Conclusions: Nasal polyps are more than one and a half times as prevalent in men than in women. The recorded prevalence of nasal polyps increases with age, with the rates peaking in those between 75 and 79 years old, and is more often in urban than rural areas.
\end{abstract}

Key words: nasal polyps, asthma, outpatient care, hospital treatment, direct costs.

\section{Introduction}

According to EPOS2020, chronic rhinosinusitis with nasal polyps (CRSwNP) represents one of the two subsets of chronic rhinosinusitis (CRS) [1]. Patients with nasal polyps account for approximately 10-30\% of all CRS patients [2-4]. This condition typically affects middle-aged and elderly patients, average age at diagnosis is 40 to 60 years, and it is more frequent in men [1, 2, 4-8].

The overall prevalence of nasal polyps in adults according to published epidemiological studies ranges from 1\% to 4\%: 2.1\% in France [6], 2.7\% in Sweden, $4.3 \%$ in Finland [9], 1-4.2\% in the USA [4, 10], 1.1-2.2\% in China $[11,12]$. However, there were methodological differences between those studies and some studies were limited to the adult or adult/adolescent population.
Compared to the subpopulation of CRS without nasal polyps (CRSsNP), the CRSwNP subpopulation is characterized by more severe disease and frequent co-morbidities, with $34 \%$ to $66.7 \%$ of patients with nasal polyps also suffering from asthma [1, 2, 13-20]. Nasal polyps often represent an important component of the clinical picture in a number of systemic diseases, including intolerance of non-steroidal anti-inflammatory drugs, cystic fibrosis, primary ciliary dyskinesia, eosinophilic granulomatosis with polyangiitis, and bronchiectasis [1,9, 17, 21-23].

The co-occurrence of two or more chronic inflammatory conditions has been widely researched and described as the multimorbidity phenomenon [24, 25]. It appears that CRSwNP may also be seen as an instance of multimorbidity with eosinophilic inflammation as the underlying cause.

Address for correspondence: Magdalena Arcimowicz MD, PhD, Otorhinolaryngology Head and Neck Surgery Department, Medical University of Warsaw, 1a Banacha St, 02-097 Warsaw, Poland, phone: +48 2259925 21, fax: +48 225992523 , e-mail: marcimowicz.wum@gmail.com Received: 15.07.2020, accepted: 14.08.2020. 
The typical features associated with CRSwNP are chronicity, a tendency to recur and a frequent need for glucocorticoid and surgical treatment, generating considerable direct and indirect socio-economic costs $[1,2,13$, $23,26]$. Generally, once diagnosed, CRSwNP is a lifelong health problem in most cases [1, 2, 26, 27].

Considering all of the above, patients with CRSwNP require long-term continuous pharmacotherapy and regular consultations with specialists or surgery (hospitalization), which generates considerable costs for the healthcare system.

\section{Aim}

The aim of the study was to analyse the reported prevalence of CRSWNP in the Polish population, including demographics and co-morbidities, and to estimate the costs of outpatient and hospital (inpatient) services financed by the National Health Fund (NHF).

\section{Material and methods}

This study follows the recommendations of the STROBE statement (www.strobe-statement.org).

\section{Study design}

A secondary data analysis was performed on data provided by the Polish NHF. The NHF database contains data on all patients in Poland who received healthcare services related to CRSwNP financed from public funds. The results were collated with information reported by the Central Statistical Office (GUS), the National Bank of Poland (NBP) and the Organisation for Economic Cooperation and Development (OECD). A similar method had been used in an earlier study [28-30].

\section{Setting}

The NHF reports covering the years 2008-2018 were used in the analysis.

\section{Variables}

CRSWNP patients were identified by the following CD10 codes: J33, J33.0, J33.1, J33.8, J33.9 [31]. The data reported by healthcare providers to the NHF (claims data) were used in the cost analysis. For each patient who received services from the health care system for CRSWNP, the sum of all disease-specific costs associated with the above ICD10 codes and incurred by the public payer was calculated (costs of procedures but not of prescription medication).

The recorded prevalence rate of CRSWNP was defined as the proportion of patients (who received outpatient or inpatient hospital services for CRSwNP at least once between 2008 and 2018) in relation to the size of the population. Patients with CRSwNP who died in 2008-2018 were excluded from the analysis.
Bias

Patients who were not insured through the NHF or those who received private health treatment were not included in the analysis.

\section{Study size}

The study population was 33,876,567 people (88.1\% of the total population) who were insured by the NHF (mandatory or voluntary insurance).

\section{Quantitative variables}

Data from the NHF registers were aggregated with co-morbidity analysis for the following 5 groups of comorbid conditions:

- group I - inflammation of the upper respiratory tract: J30-J32, J34-J39, - group II - bronchitis: J40-J42,

- group III - emphysema: J43, J47,

- group IV - other pulmonary disease: J44,

- group V - asthma: J45, J46.

\section{Statistical analysis}

Statistical analyses were performed using Statistica 10, SAS EG 7.1 and Excel. Statistical significance tests were not performed, since the NHF data refer to the entire population of Poland.

\section{Results}

\section{Descriptive data}

In 2008-2018, the number of patients receiving outpatient or hospital services related to CRSwNP ranged from 29,900 to 32,500 annually. In 2018, 28,200 patients attended 58,200 ambulatory visits for CRSwNP (2.06 per patient) and 4,400 patients had 4,700 hospital admissions (1.06 per patient), Table 1.

\section{Main results}

The recorded prevalence of CRSWNP in Poland was 52.0 per 10,000 population (64.6/10,000 for men, 40.2/10,000 for women) and varied: $\mathrm{a}$ ) between administrative regions: from 43.1/10,000 to 62.7/10,000; b) 60.0/10,000 in cities (75.3/10,000 among men and 46.3/10,000 among women) and 39.9/10,000 in rural areas (49.1/10,000 among men and 30.7/10,000 among women).

\section{Outcome data}

CRSwNP was much more frequent in patients aged 55-59 (98.1/10000) and 75-79 years (98.7/10,000). Among men, the highest prevalence was in the 75-79 age group (164.3/10,000). Among women, prevalence peaked in the 55-59 age group $(75.1 / 10,000)$ (Figure 1).

In 2008-2018, the NHF spent PLN 15.1 million to PLN 21.4 million (EUR 4.0 to 5.3 million or USD 4.5 to 7.1 mil- 
Table 1. Outpatient visits and hospital admissions related to CRSWNP (ICD-10: J33) financed by the NHF in 2008-2018

\begin{tabular}{lccccccccccc}
\hline Parameter & \multicolumn{10}{c}{ Year } \\
\cline { 2 - 12 } & $\mathbf{2 0 0 8}$ & $\mathbf{2 0 0 9}$ & $\mathbf{2 0 1 0}$ & $\mathbf{2 0 1 1}$ & $\mathbf{2 0 1 2}$ & $\mathbf{2 0 1 3}$ & $\mathbf{2 0 1 4}$ & $\mathbf{2 0 1 5}$ & $\mathbf{2 0 1 6}$ & $\mathbf{2 0 1 7}$ & $\mathbf{2 0 1 8}$ \\
\hline No. of outpatients & 28,689 & 28,913 & 27,698 & 28,966 & 29,799 & 29,531 & 29,969 & 29,237 & 29,054 & 28,866 & 28,205 \\
\hline No. of outpatient visits & 56,929 & 57,157 & 55,150 & 58,425 & 60,331 & 60,005 & 61,301 & 60,309 & 60,445 & 59,278 & 58,176 \\
\hline No. of inpatients & 8,572 & 7,798 & 7,917 & 7,564 & 7,160 & 6,502 & 6,238 & 5,781 & 5,377 & 4,925 & 4,449 \\
\hline No. of admissions & 9,302 & 8,389 & 8,492 & 8,125 & 7,757 & 6,979 & 6,771 & 6,212 & 5,804 & 5,222 & 4,717 \\
\hline
\end{tabular}

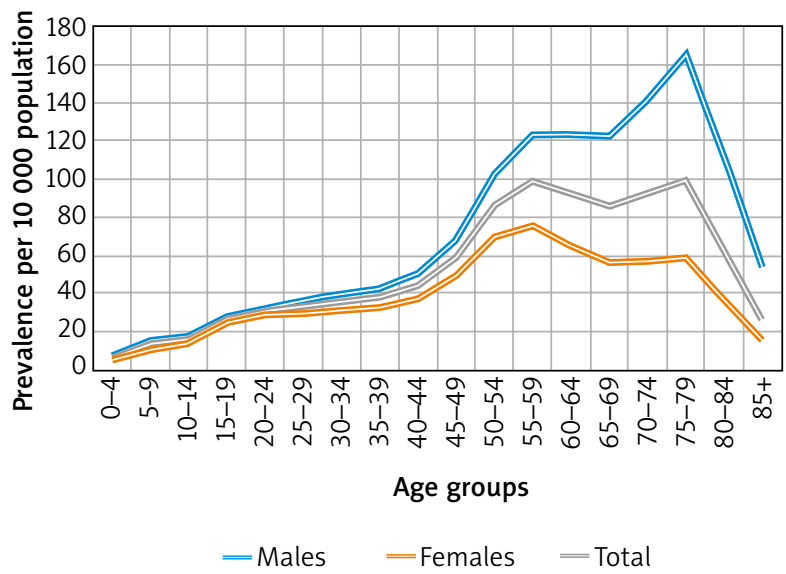

Figure 1. Nasal polyps (ICD-10: J33): recorded prevalence per 10,000 population in 2018 by age cohort

lion) annually on healthcare services for CRSwNP. The figure for 2018 was PLN 17.2 million/EUR 4.0 million/ USD 4.7 million (Table 2). Hospital services accounted for $77.4 \%$ of the total cost.

The cost per patient (including both out- and inpatient services) varied between administrative regions of Poland from PLN 260.10 per patient (EUR 61.02/USD 71.98) to PLN 1,122.31 (EUR 263.31/USD 310.60), with a mean of PLN 568.91 (EUR 133.48/USD 157.44). The highest level of costs per patient was incurred in regions where the highest share of hospital services was also observed.

\section{Other analyses}

In 2018, the percentage of all CRSwNP patients who also received healthcare services for other respiratory tract diseases was $44.4 \%$ for group I diseases, $0.9 \%$ for group II, 0.6\% for group III, 5.9\% for group IV and $22.8 \%$ for group $\vee$ (Figure 2).

\section{Discussion}

\section{Key results}

The following statements can be formulated as outcomes of this study based on NHF-registered patients with nasal polyps: 1) CRSwNP prevalence is 52.0/10,000 total population $(0.52 \%)$, being higher among men
$(64.6 / 10,000)$ than women $(40.2 / 10,000)$. 2) The highest prevalence by sex is in the group of 75-79-year-old men (164.3/10,000) and 55-59-year-old women (75.1/10,000). 3) CRSwNP is more common in cities $(60.0 / 10,000) \mathrm{com}$ pared to rural areas $(39.95 / 10,000)$. 4) The most common co-morbidities of CRSwNP are diseases of the upper respiratory tract (44.4\%) and of the lower airways, among which asthma has the highest prevalence (22.8), followed by COPD (5.9\%). 5) The prevalence of asthma comorbidity rose by about 5 percentage points between 2008 and 2018. 6) CRSwNP patients attended on average 2 outpatient visits and among hospitalized subjects, the admission rate was 1.06 per year. 7) The number of ambulatory visits remained at a similar level in 2008-2018, while the number of hospital admissions decreased by half. 8) Over $77 \%$ of public expenses (NHF) for CRSwNP is the cost of inpatient (hospital) services. 9) Data are presented for the total population, covering all age groups.

\section{Interpretation}

The recorded prevalence of CRSWNP estimated in the present study was 52.0 per 10,000 population. In a previous Polish epidemiological study based on a total of 18,617 questionnaires, the recorded prevalence of nasal polyps was $1.1 \%$ of respondents in all age groups, i.e. children and adults (6-7, 13-14 and 20-44 age groups). It was higher (1.5\%) when limited to adults only (20-44 years old) [32], which is close to CRSwNP prevalence rates reported from other European and American studies (1-4\% of the adult population) [1, 2, 4-10, 23, 33]. Based on the EPOS2020 recommendations, the global prevalence of CRSWNP and CRSSNP is estimated at $11-12 \%$ [13, 26, 34, 35], but at 2.2-10.8\% in Asia [12, 36]. No studies, however, have analysed the proportion of patients currently receiving treatment for CRSWNP (i.e. those remaining in treatment), in comparison with the total number of NP patients in the population. Compared to the previous epidemiological study carried out in Poland [32], our present work seems to offer some assessment of the problem, suggesting that a large proportion of patients with nasal polyps (at least half) do not receive regular treatment or even do not seek medical attention.

Similarly to some earlier reports [2, 6, 7, 17], our study demonstrated a higher prevalence of CRSWNP in men than in women, although not all authors agree that nasal 


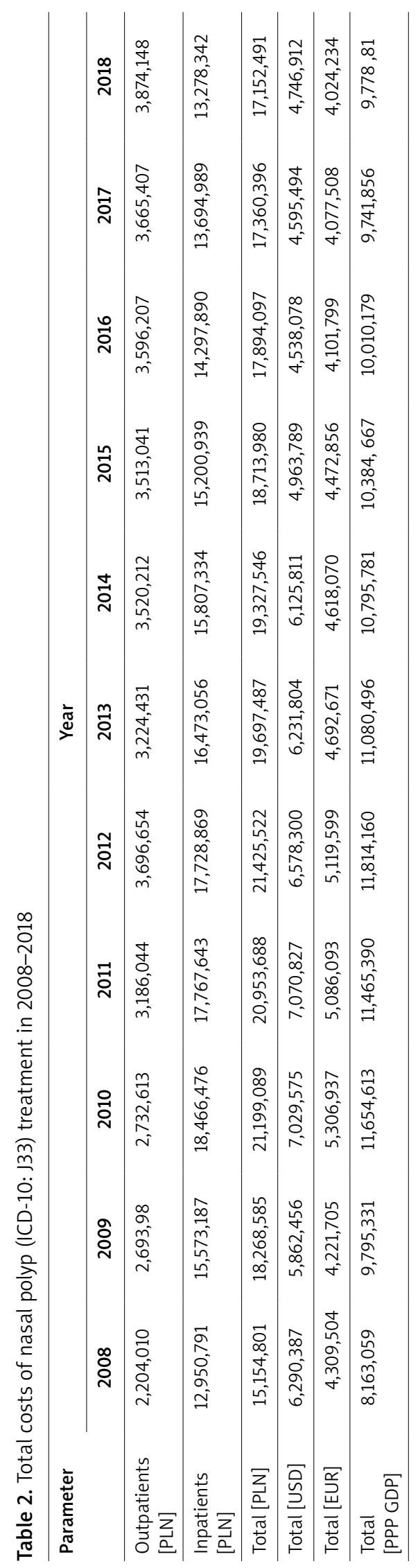

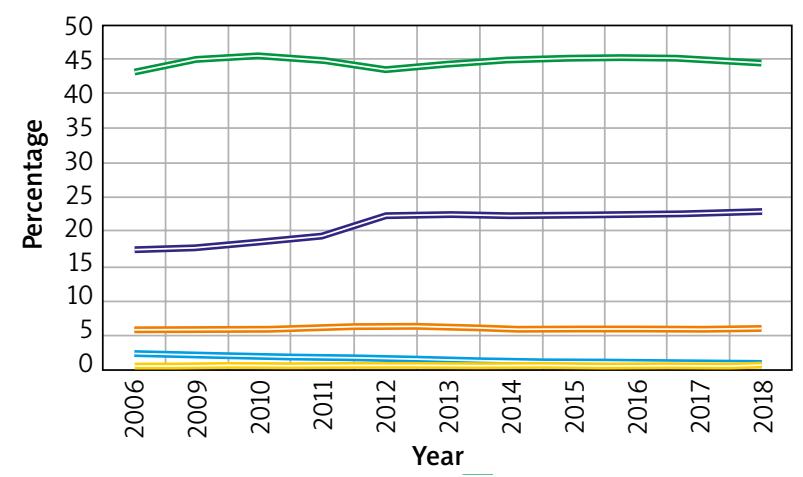

= Group I (ICD-10): J30-J32; J34-J39 = Group II (ICD-10): J40-J42 = Group III (ICD-10): J43, J47 = Group IV (ICD-10): J44

= Group V (ICD-10): J45, J46

Figure 2. Co-occurrence of certain respiratory tract diseases in patients with CRSwNP. Group I (J30-J32; J34-J39): inflammation of the upper respiratory tract, including rhinitis, rhinosinusitis, pharyngitis/tonsillitis and laryngitis and laryngotracheitis; group II (J40-J42): bronchitis; group III (J43, J47): emphysema and bronchiectasis; group IV (J44): COPD; group $\mathrm{V}(\mathrm{J} 45, \mathrm{J46})$ : asthma and status asthmaticus

polyps are significantly more common in males [6, 13]. In patients with co-existing CRSwNP and asthma, both sexes were equally affected [1], but women had more severe disease [2]. As in other available epidemiological studies $[1,2,6,7]$, we found that the proportion of patients with CRSwNP in the population increased with age and peaked in the age range of 55-59 and 74-79 years. The first peak is related to the age range of highest recorded prevalence in the female population. The average age at diagnosis is 42 years [1], which indicates that NP is in fact a life-long health problem often requiring decades of specialist health care. The prevalence rates estimated in the present study dropped sharply in all cases over the age of 79 , which could partly be associated with the life expectancy figures of 74 years for men and 81.8 years for women in Poland [37] and, possibly, the development of other diseases common in the elderly which require a prioritized treatment. People with rhinitis and asthma, with multimorbidities in particular, have a shorter life expectancy [37]. Obstructive respiratory diseases are confirmed risk factors for cardiovascular disease, including heart failure, cerebrovascular disease, metabolic disease and diabetes [38, 39]. Still, it may be hypothesized that elderly patients who suffer from a number of concurrent systemic diseases that are often serious and exert a significant impact on their quality of life (dementia, diabetes, circulatory failure, etc.) are no longer concerned about their symptoms of nasal polyposis. Healthcare professionals who are involved in their care likewise tend to ignore this problem, and the diagnosis identified by the ICD-10 code J33 is not often encountered in medical statistics. At the same time, people born before 1940 had 
limited access to endoscopic diagnostics when they were at a typical age when nasal polyps are first diagnosed.

Nasal polyps are extremely rare in children, which is confirmed by the present study and was also shown in previous papers [1,32].

The differences in CRSwNP prevalence between urban and rural areas were also noted in the previous study [32], but the finding of uneven prevalence in different administrative regions is difficult to interpret. Probably, some other factors such as air pollution or ozone concentration play a role there, which merits further research.

Outpatient visit and hospital admission counts depend on organizational solutions in the healthcare system. This is probably the reason behind the recorded low rate of outpatient visits in Poland. This also leads to low costs especially because the mean cost of an ambulatory visit is PLN 66.6 (EUR 15.62/USD 18.43), which means that in most cases the physical examination of the nasal cavity was limited to a rhinoscopy. Only a small proportion of the patients underwent a nasal endoscopy performed by an ENT specialist, which is nearly 5-fold more expensive than non-endoscopic evaluation. Additionally, the analysis of costs and frequency of visits covers specialist care only, excluding continuation of treatment in primary care. The cost of medical care of CRSWNP patients provided by GPS is not registered by the NHF.

The rising costs over the past decade (2008-2018) of ambulatory visits (outpatient care) and a fall in the number of hospital admissions are probably the result of increasingly frequent nasal glucocorticosteroid treatment of nasal polyps and improved implementation of EPOS2020 recommendations. This observation merits further research.

Hospital inpatient services account for nearly $80 \%$ of all costs reimbursed by NHF procedures, with the mean cost of a single hospitalization in 2018 amounting to PLN 2,815 (EUR 660.44/USD 779.04). This is much lower than in other countries [13]. According to American sources, the annual cost of treating a patient with CRSwNP may be nearly USD 27,000 [17]. Co-existing asthma and NSAID intolerance have significant adverse effects on the course of CRSWNP and its severity, being associated with frequent failure of medical or surgical treatment, with high recurrence and reoperation rates [1, 13, 40, 41]. The NHF database does not contain information on the costs of prescription medication and the costs related to absence from work due to CRSWNP.

The co-occurrence of asthma and CRSwNP (22.8\%) was lower than previously reported in other studies, where such co-morbidity varied from $26 \%$ to $49.6 \%$ [1, $2,13,17,19]$, but higher than the prevalence of asthma in the general population, estimated at $8.2 \%$ in the European Union [42] and, in Poland, at 12\% (symptoms of asthma) or 4.72\% (self-reported asthma) and 11\% (asthma diagnosed by a doctor) [43].
According to Frendo et al., subjects with CRSwNP enrolled in most published clinical studies are candidates for sinus surgery for very advanced disease. In those patients, asthma is often first diagnosed during trial enrolment or when they are qualified for surgery [14]. It may be hypothesized that in the population of patients identified by the ICD-10, co-morbid asthma was underdiagnosed, which has also been pointed out by the Global Allergy and Asthma European Network (GALEN) in a paper published this year [17]. The ECAP results [43] clearly demonstrated that asthma was underdiagnosed in the Polish population and the same may be suspected among patients with CRSwNP.

Information on the co-existence of CRSWNP and COPD is limited, although Wu et al. described a CRSWNP phenotype co-existing with non-eosinophilic asthma and smoking, which could have included some cases of COPD and asthma-COPD overlap syndrome (ACOS) [20, 44]. Generally, the incidence of COPD in the general population is almost twice as common compared to our results $[45,46]$. The GALEN paper cited above found a more frequent co-existence of COPD and CRS, but only without nasal polyps [17]. Guilemany et al. observed a high prevalence of rhinosinusitis and nasal polyps in bronchiectasis [21]. In the present analysis, we assessed the frequency of group III diseases (bronchiectasis and emphysema) jointly so it is difficult to compare our results with earlier reports.

The considerable diversity of the diseases in group I does not enable a more detailed comparative analysis of the data, especially because these conditions are very common in the population. However, undoubtedly, CRSWNP, owing to its uniqueness, has an important impact on the concomitant appearance of inflammatory diseases of the upper airways. At the same time, it is well known that, particularly, chronic rhinitis is an invariable feature of the clinical picture in CRSWNP, and allergic rhinitis is observed in up to two-thirds of patients with NP [17].

Co-morbidities seem to have a significant impact on the course and control of the primary disease [24, 25]. Our study clearly shows this link between CRSwNP and asthma. Singh et al. demonstrated that chronic rhinitis/ sinusitis is a high-risk co-morbidity for 30-day hospital readmission of patients with asthma and COPD [47]. In a study of 34,468 asthma patients, Lisspers et al. confirmed that nasal polyps are among the co-morbidities associated with the highest risk of an asthma exacerbation [18]. In the same paper, they convincingly demonstrated that the presence of concomitant asthma and nasal polyps was associated with age and peaked after the age of 50 years. The costs of treatment increase significantly in patients with united airway disease [18]. The $5 \%$ increase in the prevalence of co-morbidity is probably the result of demographic changes in Poland (a rising elderly population of about 2 million and a dwindling 
paediatric population of about 2 million). Changes in life expectancy also influence CRSwNP prevalence, because this condition is typically associated with old age. This suggests that the nasal polyp population will be rising in line with the longer life expectancy.

The association of rhinitis and rhinosinusitis with nasal polyps has been frequently described in the literature $[1,14,15,27]$, but the co-occurrence of pharyngitis/tonsillitis or tracheitis has not been reported previously.

The NHF data, however, are not appropriate for evaluating the level of CRSwNP control or obtaining information on the indirect socio-economic costs. Nevertheless, it is generally expected that the NHF should take it into consideration that demographic changes influence public expenses and organization of the healthcare system also with regard to CRSWNP and co-morbidities.

\section{Limitations}

The NHF register is used by the public payer (NHF) in settling contracts with healthcare providers. There are no data from private healthcare providers so the prevalence rates presented in this analysis may be underestimated.

The use of the ICD-10 code $J 33$ as a discriminator allowed precise identification of patients with nasal polyps. However, it must be remembered that for some patients with nasal polyps the diagnosis was coded as the ICD-10 code 132 (chronic sinusitis) and they were not included in the analysis. These patients do not seem to account for a large percentage of CRSWNP cases as the NHF accounting procedures require precise documentation (ICD10 coding) of the diagnoses.

\section{Strengths}

The study was based on the official NHF data for 10 reference periods (the years 2008-2018) characterized by high levels of standardisation and comparability and, importantly, referring to the total population of Poland.

The NHF data are an important source of information on the utilisation and costs of treatment in patients with CRSwNP delivered through the single public payer healthcare system. They include demographic data and information on the co-morbid conditions of nasal polyposis and, in particular, NP associated with bronchial asthma.

\section{Conclusions}

Nasal polyps are more than one and a half times as prevalent in men than in women. The recorded prevalence of nasal polyps increases with age and the rates peak in men aged 75-79 years and in women aged 55-59 years. Higher prevalence of CRSWNP is recorded in urban areas compared to rural areas. Most common recorded co-morbidities in nasal polyps patients were other inflammatory diseases of the upper airways and asthma. The NHF data in comparison with a population-wide epi- demiological study shows that a large proportion of patients with nasal polyps do not receive regular treatment or even do not seek medical attention. The treatment of patients with nasal polyps is not cost-effective. Hospital treatment accounts for $77 \%$ of the treatment costs reimbursed by the NHF, while some of the procedures could be effectively performed on an outpatient basis.

\section{Conflict of interest}

The authors declare no conflict of interest.

\section{References}

1. Fokkens WJ, Lund VJ, Hopkins C, et al. European position paper on rhinosinusitis and nasal polyps 2020. Rhinology 2020; 50 Suppl. 29: 1-464.

2. Stevens WW, Schleimer RP, Kern RC. Chronic rhinosinusitis with nasal polyps. J Allergy Clin Immunol Pract 2016; 4: 565-72.

3. Bhattacharyya N. Influence of polyps on outcomes after endoscopic sinus surgery. Laryngoscope 2007; 117: 1834-8.

4. Palmer JN, Messina JC, Biletch R, et al. A cross-sectional, population-based survey of U.S. adults with symptoms of chronic rhinosinusitis. Allergy Asthma Proc 2019; 40: 48-56.

5. Johansson L, Akerlund A, Holmberg K, et al. Prevalence of nasal polyps in adults: the Skovde population-based study. Ann Otol Rhinol Laryngol 2003; 112: 625-9.

6. Klossek JM, Neukirch F, Pribil C, et al. Prevalence of nasal polyposis in France: a cross-sectional, case-control study. Allergy 2005; 60: 233-7.

7. Larsen K, Tos M. The estimated incidence of symptomatic nasal polyps. Acta Otolaryngol 2002; 122: 179-82.

8. Settipane GA. Epidemiology of nasal polyps. Allergy Asthma Proc 1996; 17: 231-6.

9. Hedman J, Kaprio J, Poussa T, Nieminen MM. Prevalence of asthma, aspirin intolerance, nasal polyposis and chronic obstructive pulmonary disease in a population-based study. Int J Epidemiol 1999; 28: 717-22.

10. Workman AD, Parasher AK, Blasetti MT, et al. Accuracy of self-reported diagnosis of chronic rhinosinusitis. Otolaryngol Head Neck Surg 2019; 160: 556-8.

11. Shi JB, Fu QL, Zhang H, et al. Epidemiology of chronic rhinosinusitis: results from a cross-sectional survey in seven Chinese cities. Allergy 2015; 70: 533-9.

12. Zhang Y, Gevaert E, Lou H, et al. Chronic rhinosinusitis in Asia. J Allergy Clin Immunol 2017; 140: 1230-9.

13. Bhattacharyya N, Villeneuve S, Joish VN, et al. Cost burden and resource utilization in patients with chronic rhinosinusitis and nasal polyps. Laryngoscope 2019; 129: 1969-75.

14. Frendo M, Hakansson K, Schwer S, et al. Asthma in ear, nose, and throat primary care patients with chronic rhinosinusitis with nasal polyps. Am J Rhinol Allergy 2016; 30: 67-71.

15. Gelardi M, Iannuzzi L, Tafuri S, et al. Allergic and non-allergic rhinitis: relationship with nasal polyposis, asthma and family history. Acta Otorhinolaryngol Ital 2014; 34: 36-41.

16. Hakansson K, Thomsen SF, Konge L, et al. A comparative and descriptive study of asthma in chronic rhinosinusitis with nasal polyps. Am J Rhinol Allergy 2014; 28: 383-7.

17. Khan A, Vandeplas G, Huynh TMT, et al. The Global Allergy and Asthma European Network (GALEN rhinosinusitis cohort: a large European cross-sectional study of chronic rhi- 
nosinusitis patients with and without nasal polyps. Rhinology 2019; 57: 32-42.

18. Lisspers K, Janson C, Larsson K, et al. Comorbidity, disease burden and mortality across age groups in a Swedish primary care asthma population: an epidemiological register study (PACEHR). Respir Med 2018; 136: 15-20.

19. Promsopa C, Kansara S, Citardi MJ, et al. Prevalence of confirmed asthma varies in chronic rhinosinusitis subtypes. Int Forum Allergy Rhinol 2016; 6: 373-7.

20. Wu D, Li L, Zhang M, et al. Two inflammatory phenotypes of nasal polyps and comorbid asthma. Ann Allergy Asthma Immunol 2017; 118: 318-25.

21. Guilemany JM, Angrill J, Alobid I, et al. United airways again: high prevalence of rhinosinusitis and nasal polyps in bronchiectasis. Allergy 2009; 64: 790-7.

22. Hellings PW, Prokopakis EP. Global airway disease beyond allergy. Curr Allergy Asthma Rep 2010; 10: 143-9.

23. Lange B, Holst R, Thilsing T, et al. Quality of life and associated factors in persons with chronic rhinosinusitis in the general population: a prospective questionnaire and clinical cross-sectional study. Clin Otolaryngol 2013; 38: 474-80.

24. Bousquet J, Anto JM, Wickman M, et al. Are allergic multimorbidities and IgE polysensitization associated with the persistence or re-occurrence of foetal type 2 signalling? The MeDALL hypothesis. Allergy 2015; 70: 1062-78.

25. Raciborski F, Bousqet J, Namyslowski A, et al. Dissociating polysensitization and multimorbidity in children and adults from a Polish general population cohort. Clin Transl Allergy 2019; 9: 4.

26. Avdeeva K, Fokkens W. Precision medicine in chronic rhinosinusitis with nasal polyps. Curr Allergy Asthma Rep 2018; 18: 25.

27. Orlandi RR, Kingdom TT, Hwang PH, et al. International consensus statement on allergy and rhinology: rhinosinusitis. Int Forum Allergy Rhinol 2016; 6 Suppl 1: S22-209.

28. Jahnz-Rozyk K, Raciborski F, Sliwczynski AM, et al. Anaphylaxis in Poland: the epidemiology and direct costs. Adv Dermatol Allergol 2017; 34: 573-9.

29. Raciborski F, Jahnz-Rozyk K, Kłak A, et al. Epidemiology and direct costs of atopic dermatitis in Poland based on the National Health Fund register (2008-2017). Adv Dermatol Allergol 2019; 36: 727-33.

30. Sliwczynski A, Brzozowska M, Iltchew P, et al. Epidemiology of asthma in Poland in urban and rural areas, based on provided health care services. Pneumonol Alergol Pol 2015; 83: 178-87.

31. WHO. International Classification of Diseases. https://icdwhoint/browse10/2016/en 2016.

32. Wojas O, Arcimowicz M, Furmańczyk K, et al. Relationship between nasal polyps, bronchial asthma, allergic rhinitis, atopic dermatitis and non-allergic rhinitis. Adv Dermatol Allergol 2020, DOI.org/10.5114/ada.2020.94400.

33. Portenko G. Prevalence of polypous rhinosinusitis among the population. Vestnik otorinolaringologii 1989; 1: 52-4.

34. Hastan D, Fokkens WJ, Bachert C, et al. Chronic rhinosinusitis in Europe: an underestimated disease. A GA(2)LEN study. Allergy 2011; 66: 1216-23.

35. Hirsch AG, Stewart WF, Sundaresan AS, et al Nasal and sinus symptoms and chronic rhinosinusitis in a population-based sample. Allergy 2017; 72: 274-81.

36. Kim JH, Cho C, Lee EJ, et al. Prevalence and risk factors of chronic rhinosinusitis in South Korea according to diagnostic criteria. Rhinology 2016; 54: 329-35.
37. Wojtyniak B, Goryński P. (eds). Sytuacja zdrowotna ludności Polski i jej uwarunkowania (Health status of Polish population and its determinants). Narodowy Instytut Zdrowia Publicznego, Państwowy Zakład Higieny Warszawa 2018; 1-492.

38. Garcia-Olmos L, Alberquilla A, Ayala V, et al. Comorbidity in patients with chronic obstructive pulmonary disease in family practice: a cross sectional study. BMC Fam Pract 2013; 14: 11.

39. Iribarren C, Tolstykh IV, Miller MK, et al. Adult asthma and risk of coronary heart disease, cerebrovascular disease, and heart failure: a prospective study of 2 matched cohorts. Am J Epidemiol 2012; 176: 1014-24.

40. Batra PS, Tong L, Citardi MJ. Analysis of comorbidities and objective parameters in refractory chronic rhinosinusitis. Laryngoscope 2013; 123 Suppl 7: S1-11.

41. Deal RT, Kountakis SE. Significance of nasal polyps in chronic rhinosinusitis: symptoms and surgical outcomes. Laryngoscope 2004; 114: 1932-5.

42. Selroos O, Kupczyk M, Kuna P, et al. National and regional asthma programmes in Europe. Eur Respir Rev 2015; 24: 474-83.

43. Samoliński B, Raciborski F, Lipiec A, et al. Epidemiologia Chorób Alergicznych w Polsce (ECAP). Pol J Allergol 2014; 1: 10-8.

44. Wu D, Bleier BS, Li L, et. al. Clinical phenotypes of nasal polyps and comorbid asthma based on cluster analysis of disease history. J Allergy Clin Immunol Pract 2018; 6: 1297$305 \mathrm{e} 1$.

45. Mannino DM, Buist AS. Global burden of COPD: risk factors, prevalence, and future trends. Lancet 2007; 370: 765-73.

46. Nizankowska-Mogilnicka E. MFBAS. Częstość występowania POChP i rozpowszechnienie palenia tytoniu w Małopolsce wyniki badania BOLD w Polsce. Pol Arch Med Wewn 2007; 117: 402-9.

47. Singh U, Wangia-Anderson V, Bernstein JA. Chronic rhinitis is a high-risk comorbidity for 30-day hospital readmission of patients with asthma and chronic obstructive pulmonary disease. J Allergy Clin Immunol Pract 2019; 7: 279-85e6. 